\title{
ADSORPTION FEASIBILITY IN THE Cr(TOTAL) IONS REMOVAL FROM WASTE PRINTING DEVELOPER
}

\section{J. KIURSKI * \\ S. ADAMOVIĆ \\ I. OROS \\ J. KRSTIĆ \\ I. KOVAČEVIĆ}

Received: 24/06/11

Accepted: 03/10/11

\author{
University of Novi Sad, Faculty of Technical Sciences
}

Trg Dositeja Obradovića 6, 21000 Novi Sad, Serbia

*to whom all correspondence should be addressed: e-mail: kiurski@uns.ac.rs

\begin{abstract}
In this article, the technical feasibility of various commercial adsorbents (activated carbon, clinoptilolite, and their mixture) for removal of $\mathrm{Cr}$ (total) ions from waste printing developer has been represent. Experimental tests were performed in laboratory batch mode. The adsorption data were analyzed using the Freundlich, Langmuir and Dubinin-Kaganer-Radushkevich (DKR) isotherm models. It was found that the Freundlich isotherm gave better results than the Langmiur and DKR models, with the corresponding correlation coefficients $\left(R^{2}\right)$ : $0.981,0.996$ and 0.997 for mixture $(\mathrm{NZ}+\mathrm{AC}), \mathrm{AC}$ and $\mathrm{NZ}$, respectively. The adsorption capacities of $\mathrm{Cr}$ (total) ions followed the order: $(\mathrm{NZ}+\mathrm{AC})>\mathrm{AC}>\mathrm{NZ}$. The adsorption efficiencies of $\mathrm{Cr}$ (total) ions removal were 38.5 to $39.9 \%$. Due to easy availability and good efficiency, the mixture of clinoptilolite and activated carbon is an ideal adsorbents for removal of $\mathrm{Cr}$ (total) ions from waste printing developer.
\end{abstract}

KEYWORDS: Heavy metals, natural adsorbents, adsorption isotherms, batch mode, printing waste.

\section{INTRODUCTION}

Electroplating, metalworking and printing industries discharge large amounts of heavy metals, including chromium $(\mathrm{Cr})$ ions, in their effluents. Several processing techniques are available to reduce the concentrations of heavy metals in wastewater, including precipitation, flotation, ionexchange, solvent extraction, adsorption, cementation onto iron, membrane processing, and electrolytic methods.

Adsorption onto activated carbon is a well-known method for removing toxic metal ions, but the high cost of activated carbon restricts its use in developing countries, with small factories in particular often being unable to support expensive wastewater treatment methods. Cheap and effective alternatives for the removal of heavy metals should reduce operating costs, reduce the prices of products, improve competitiveness, and benefit the environment. The adsorption abilities of a number of low-cost adsorbents (e.g., cheap zeolites, clay, coal fly ash, sewage sludge, agriculture waste and biomass) have been determined for the removal of heavy metals from wastewater (ThingChu Hsu, 2009; Babel and Kurniawan, 2003; Jiuhui, 2008; Kiurski et al., 2008; 2009; 2010a; Oke et al., 2008; Thompson et al., 2001; Rožić et al., 2004).

Processing of plates consumes three primary resources: chemistry to develop or process the plates, energy to run the processing unit, and water to rinse the plate, dilute the chemistry, or clean the unit. Similarly, processing generates waste which must be disposed of, in the form of spent chemistry, waste water, and containers. Each plate type and process consumes different amounts of these resources, depending on the imaging laser, emulsions used, and chemical and physical reactions required to develop or wash-up the plate. All waste matters are specialists in providing a one - stop waste chemical and hazardous waste disposal and recycling service of up to $99 \%$ of all printing waste, removing the need for multiple waste management suppliers (Thompson et al., 2001). From 
small independent printers to the larger multi national print and mailing suppliers, all waste matters can provide a tailored waste management service to ensure hazardous waste recycling problems are a thing of the past.

The role of printing developer in the plate or film development process is to convert the latent images to visible ones. The most present components of fresh printing developer are potassium silicate, sodium silicate, sodium carbonate, potassium hydroxide, D-sorbitol, sodium sulfite, potassium bromide, metol [4-(methylamino)phenol sulfate] and hydroquinone. After the development process, waste printing developer is enriched by plate surface compounds: novolac, organic polymeric binders, photosensitive compounds, dyes and some others. Heavy metal, chromium, found in waste printing developer comes from the dye residue.

Waste printing developer needs a proper treatment and disposal if its $\mathrm{pH}$ value is strongly alkaline $(\geq 12.5)$. Thus it may be a potential hazard if discharged into water recipients. Also, cumulative organics considerably increase the chemical oxygen demand and the toxicity of waste. The requirements for an adequate treatment of waste developer are to be met, to prevent increased concentrations of some metals and organic pollutants from the printing industry (Rožić et al., 2004; Vengris et al., 2004).

The present study was undertaken to evaluate the efficiency of an activated carbon, clinoptilolite, and their mixture as adsorbents for removal of chromium ions in waste printing developer. In this paper, we have reported the applicability of the adsorption of chromium (total) ions onto desired natural adsorbents.

\section{MATERIAL AND METHODS}

Samples of fresh and waste printing developer were taken from the pre-press unit of a Novi Sad (Serbia) offset printing plant.

The adsorption of $\mathrm{Cr}$ (total) ions from waste printing developer was investigated using natural zeolite (NZ, clinoptilolite, High Tech zeolite producer, Turkey), activated carbon (AC, Norit Row 0.8 Supra, USA) and the mixture of NZ and AC (NZ+AC), as adsorbents (Kiurski et al., 2010b).

All the chemicals were of analytical reagent grade (Merck, Germany). Equilibrium time were determined with working solution prepared by diluting the stock metal solution $\left(1000 \mathrm{mg} \mathrm{L}^{-1}\right)$ with deionized water in order to obtain the real concentration of $4.674 \mathrm{mg} \mathrm{L}^{-1} \mathrm{Cr}$ (total) ions in waste printing developer (measured by ICP-MS). The known amount of the each adsorbent $(0.2 \mathrm{~g})$ was shaken (shaking speed $26 \mathrm{rpm}$ ) with $25 \mathrm{~mL}$ of working solution, while the time varied from 60 to 110 $\mathrm{min}$. At the end of the predetermined time interval, the solutions were centrifuged for 10 minutes at $3000 \mathrm{rpm}$ (Centrifuge, Tehtnica Železniki, Slovenia) and then filtered through a quantitative cellulose filter paper (Advantec, grade $5 \mathrm{C}$ ). Concentration of $\mathrm{Cr}$ (total) ions were determined by Inductively Coupled Plasma Mass Spectrometry (ICP-MS), using a PerkinEImer Elan 5000 mass spectrometer. The adsorption study was carried out by shaking different amounts of NZ, AC or NZ+AC (0.04-0.24 $\mathrm{g}$ with an increment of $0.04 \mathrm{~g}$ ) in $100 \mathrm{~mL}$ stopper bottles, with $25 \mathrm{~mL}$ of waste printing developer at $\mathrm{pH} 10.9$, temperature $23.4^{\circ} \mathrm{C}$ and shaking speed $26 \mathrm{rpm}$. At the end of the equilibrium adsorption process, the residual $\mathrm{Cr}$ (total) concentrations were determined in the same way as in the equilibrium time experiment.

\section{RESULTS}

The adsorption experimental data of $\mathrm{Cr}$ (total) ions in relation of contact time are shown in Figure 1. The adsorption of $\mathrm{Cr}$ (total) ions increased first and then remained constant until the equilibrium was attained, which occurred after 90 minutes for all the adsorbents. Figure 1 reveals that the curves are single, smooth, and continuous, leading to saturation, suggesting the possible monolayer coverage of the chromium ions on the carbon and clinoptilolite surfaces (Arivoli et al., 2007).

Based on the trend of the curves in Figure 1, it can be predicted that the optimal contact time for adsorption on (NZ+AC) would be also 90 minutes.

The experimental data analyzed according to the linear form of the Langmuir (Rao et al., 2006, Kocaoba et al., 2007), Freundlich (Sprynskyy et al., 2006; Kocaoba et al., 2007) and Dubinin Kaganer - Radushkevich (DKR) (Erdem et al., 2004) isotherms. 
The Langmuir isotherm represented by the following equation (1):

$1 / Q_{e}=1 / Q_{m} b 1 / C_{e}+1 / Q_{m}$

where $C_{e}$ is the equilibrium concentration of $\operatorname{Cr}$ (total) ions $\left(\mathrm{mg} \mathrm{L}^{-1}\right), \mathrm{Q}_{e}$ is the amount adsorbed at equilibrium ( $\mathrm{mg} \mathrm{kg}^{-1}$ ) and $\mathrm{Q}_{\mathrm{m}}$ and $\mathrm{b}$ is Langmuir constants related to adsorption efficiency and energy of adsorption, respectively. The linear plots of $1 / Q_{e}$ versus $1 / C_{e}$ suggest the applicability of the Langmuir isotherms (Figure 2). Values of $Q_{m}$ and $b$ were determined from slope and intercepts of the plots and are presented in Table 1. The experimental data of Langmuir adsorption parameters have negative slopes and intercepts, which suggesting that the adsorption behavior of the tested systems does not follow the assumption of the Langmuir approach.

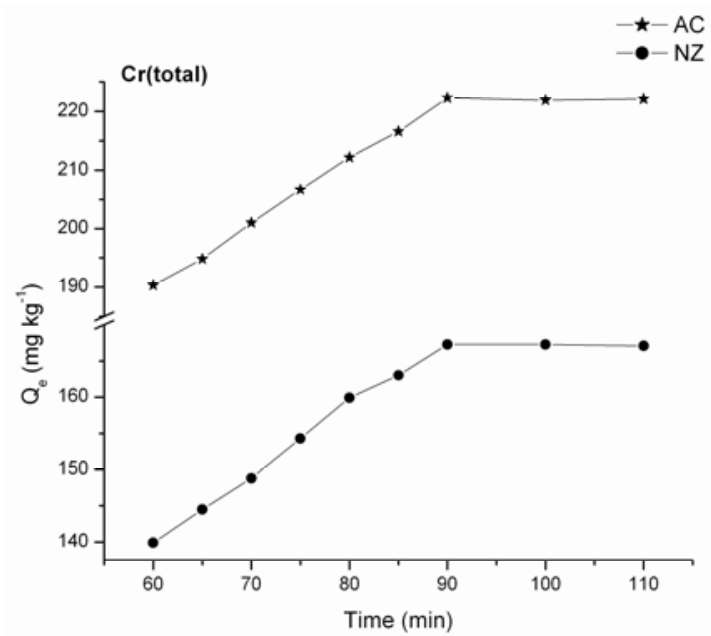

Figure 1. Effect of contact time on adsorption of $\mathrm{Cr}$ (total) ions

by $\mathrm{NZ}$ and $\mathrm{AC},[\mathrm{Cr}($ total $)]=4.674 \mathrm{mg} \mathrm{L}^{-1} ; \mathrm{pH}=$

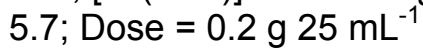

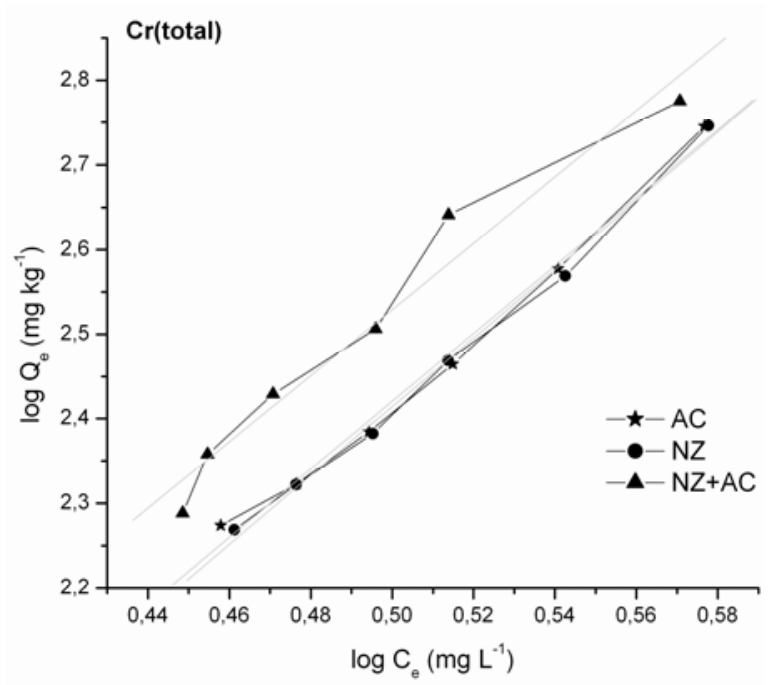

Figure 2. Langmuir isotherm for the adsorption of $\mathrm{Cr}$ (total) ions by various adsorbents

Table 1. Langmuir adsorption parameters for various adsorbents

\begin{tabular}{|c|c|c|c|}
\hline \multicolumn{4}{|c|}{$\begin{array}{c}\text { Langmuir adsorption isotherm constants } \\
\text { for Cr(total) ions }\end{array}$} \\
\hline Adsorbent & $\mathrm{Q}_{\mathrm{m}}\left(\mathrm{mg} \mathrm{kg}^{-1}\right)$ & $\mathrm{b}$ & $\mathrm{R}^{2}$ \\
\hline $\mathrm{NZ}$ & -100.50 & -0.23 & 0.995 \\
$\mathrm{AC}$ & -102.35 & -0.22 & 0.996 \\
\cline { 2 - 4 }$(\mathrm{NZ}+\mathrm{AC})$ & -112.11 & -0.23 & 0.912 \\
\hline
\end{tabular}

The Freundlich equation was also employed for the adsorption of $\mathrm{Cr}$ (total) ions on the adsorbents. The Freundlich isotherm have represented as in equation (2):

$\log Q_{e}=\log K_{f}+1 / n \log C_{e}$

where $Q_{e}$ is the amount of $\mathrm{Cr}$ (total) ions adsorbed $\left(\mathrm{mg} \mathrm{g}^{-1}\right), C_{e}$ is the equilibrium concentration of $\mathrm{Cr}$ (total) ions in solution $\left(\mathrm{mg} \mathrm{L}^{-1}\right)$ and $\mathrm{K}_{\mathrm{f}}$ and $\mathrm{n}$ are constants incorporating all factors affecting the adsorption capacity and intensity of adsorption, respectively. Linear plots of $\log Q_{e}$ versus $\log C_{e}$ shows that the adsorption of $\mathrm{Cr}$ (total) ions follows the Freundlich isotherm (Figure 3). 


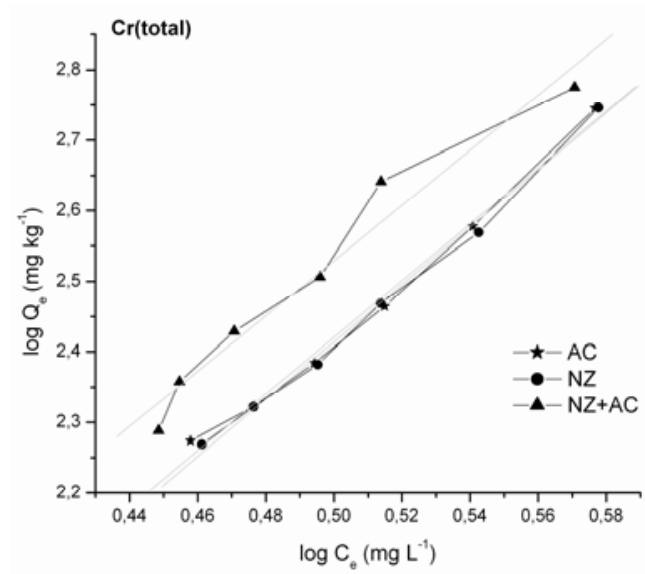

Figure 3. Freundlich isotherm for the adsorption of $\mathrm{Cr}$ (total) ions by various adsorbents

The calculated values of $K_{f}$ and $n$, Table 2, show the increase of electrostatic force like Van der Waal's between the adsorbents surface and $\mathrm{Cr}$ (total) ions due to the increasing of negative charges on the adsorbent surface. However, the values clearly show the dominance in adsorption capacity. The intensity of adsorption is an indicative of the bond energies between chromium ions and adsorbent and the possibility of slight chemisorptions rather than physisorption of chromium ions (Arivoli et al., 2007). However, the multilayer adsorption of chromium ions through the percolation process may be possible. The values of $\mathrm{n}$ were lower than one indicating the adsorption is less favorable.

Table 2. Freundlich adsorption parameters for various adsorbents

\begin{tabular}{cccc}
\hline Freundlich adsorption isotherm constants for \\
Cr(total) ions \\
\hline Adsorbent & $\mathrm{K}_{\mathrm{f}}\left(\mathrm{mg} \mathrm{kg}^{-1}\right)$ & $\mathrm{n}$ & $\mathrm{R}^{2}$ \\
\hline $\mathrm{NZ}$ & 2.42 & 0.25 & 0.997 \\
$\mathrm{AC}$ & 2.59 & 0.25 & 0.996 \\
\cline { 2 - 4 }$(\mathrm{NZ}+\mathrm{AC})$ & 3.73 & 0.26 & 0.981 \\
\hline
\end{tabular}

From Table 2 it can be concluded that adsorbent (NZ+AC) is the most effective for the $\mathrm{Cr}$ (total) ions removal from printing developer because its adsorption capacity is highest $\left(3.73 \mathrm{mg} \mathrm{kg}^{-1}\right)$.

The DKR isotherm for describing the adsorption of metal ions on all adsorbents was used in the following form equation (3):

$\ln Q_{e}=\ln X_{m}-\beta \varepsilon^{2}$

Where $Q_{e}$ is the amount of $\operatorname{Cr}\left(\right.$ total) ions adsorbed per unit weight of adsorbent $\left(\mathrm{mg} \mathrm{kg}^{-1}\right), X_{m}$ is the maximum adsorption capacity $\left(\mathrm{mg} \mathrm{kg}^{-1}\right), \beta$ is the coefficient of activity related to the mean sorption energy $\left(\mathrm{mol}^{2} \mathrm{~J}^{-2}\right)$, and $\varepsilon$ is the Polanyi potential, which is equal to (4):

$\varepsilon=R T \ln \left(1+1 / C_{e}\right)$

Where $R$ is the gas constant $\left(\mathrm{J} \mathrm{mol}^{-1} \mathrm{~K}^{-1}\right)$ and $T$ is the temperature $(K)$. The values for $\beta$ and $X_{m}$ are obtained from the slope and intercept of the plot of $\ln Q_{e}$ versus $\varepsilon^{2}$.

The adsorption space in the vicinity of a solid surface is characterized by a series of equipotential surfaces having the same adsorption potential. The adsorption potential is independent of the temperature, but depends on the nature of the sorbent and sorbate. The adsorption energy can be calculated using the following equation (5) (Erdem et al., 2004):

$E=1 / \sqrt{-2 \beta}$

The DKR plots of $\ln Q_{e}$ in function of $\varepsilon^{2}$ for the adsorption of investigated $\mathrm{Cr}$ (total) ions on the tested adsorbents are shown in Figure 4. The DKR parameter $(\beta)$ gives negative values for all the adsorbents, because it was calculated from a negative slope, while the parameter $X_{m}$ was calculated 
from the intercept. The values of the DKR parameters and the corresponding correlation coefficients are summarized in Table 3.

Table 3. DKR adsorption parameters for various adsorbents

\begin{tabular}{ccccc}
\hline \multicolumn{5}{c}{$\begin{array}{c}\text { DKR adsorption isotherm constants } \\
\text { for Cr(total) ions }\end{array}$} \\
\hline Adsorbent & $\mathrm{X}_{\mathrm{m}}\left(\mathrm{mg} \mathrm{kg}^{-1}\right)$ & $\beta\left(\mathrm{mol}^{2} \mathrm{~J}^{-2}\right)$ & $\mathrm{E}\left(\mathrm{J} \mathrm{mol}^{-1}\right)$ & $\mathrm{R}^{2}$ \\
\hline $\mathrm{NZ}$ & 3453.90 & -0.5534 & 0.95 & 0.988 \\
\cline { 2 - 5 } AC & 3355.68 & -0.5427 & 0.96 & 0.969 \\
\cline { 2 - 5 }$(\mathrm{NZ}+\mathrm{AC})$ & 2903.38 & -0.4525 & 1.05 & 0.974 \\
\hline
\end{tabular}

The positive values of adsorption energy correspond to the endothermic process for all investigated adsorbents.

The efficiency of adsorbent (NZ+AC) is $39.9 \%$, Figure 5 . The efficiency of adsorbent was calculated from the equation (6):

$$
E=100\left(C_{0}-C_{e}\right) / C_{0}
$$

Where $\mathrm{E}$ is the adsorption efficiency (\%), $\mathrm{C}_{0}$ is the initial concentration of $\mathrm{Cr}$ (total) ions $\left(\mathrm{mg} \mathrm{L}^{-1}\right), \mathrm{C}_{\mathrm{e}}$ is the equilibrium concentration of $\mathrm{Cr}$ (total) ions $\left(\mathrm{mg} \mathrm{L}^{-1}\right.$ ) (Sprynskyy et al., 2006; Kocaoba et al., 2007).

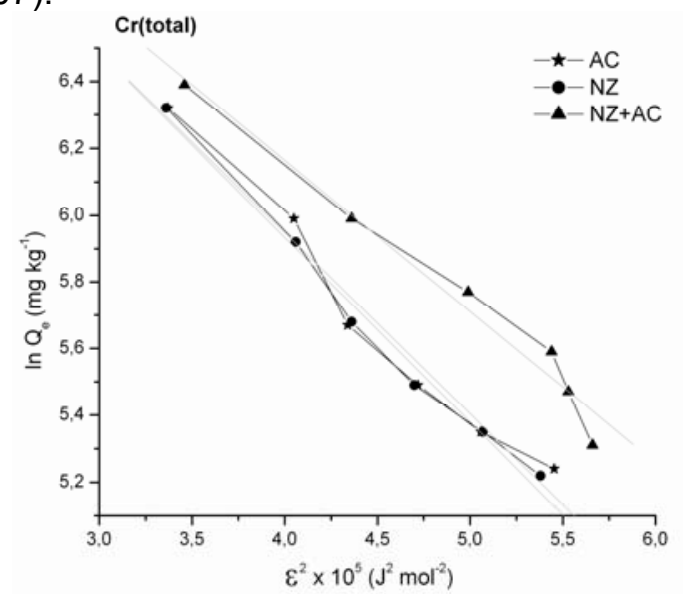

Figure 4. DKR isotherm for the adsorption of $\mathrm{Cr}$ (total) ions by various adsorbents

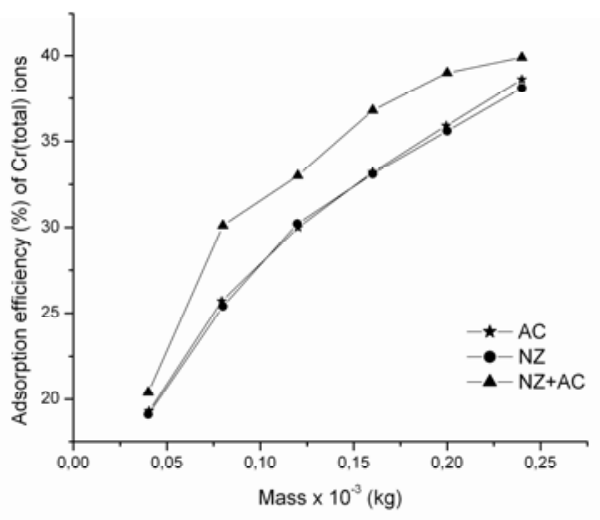

Figure 5. Efficiency of adsorbents in $\mathrm{Cr}$ (total) ions removal

The adsorption efficiencies of the adsorbents used in the removal of $\mathrm{Cr}$ (total) ions are illustrated in Table 4. The concentration of $\mathrm{Cr}$ (total) ions of waste printing developer is almost 3 times higher in relation to the fresh developer. It is evident that after the adsorption process, concentration of $\mathrm{Cr}$ (total) ions decreased approximately 1.5 times, or almost $33 \%$.

Table 4. Concentrations of $\mathrm{Cr}$ (total) ions in the printing developers

\begin{tabular}{ccccc}
\hline \multicolumn{5}{c}{ Concentration $\left(\mathrm{mg} \mathrm{L}^{-1}\right) \pm \mathrm{RD}$} \\
\hline \multicolumn{4}{c}{ After adsorption } \\
\hline $\begin{array}{c}\text { Fresh } \\
\text { developer }\end{array}$ & $\begin{array}{c}\text { Waste } \\
\text { developer }\end{array}$ & $\mathrm{NZ}^{*}$ & $\mathrm{AC}$ & $\mathrm{NZ}+\mathrm{AC}$ * \\
\hline $1.528 \pm 0.076$ & $4.674 \pm 0.234$ & $3.258 \pm 0.163$ & $3.251 \pm 0.163$ & $3.122 \pm 0.156$ \\
\hline *Waste developer after adsorption on NZ, AC or (NZ+AC)
\end{tabular}

\section{CONCLUSIONS}

The removal of $\mathrm{Cr}$ (total) ions from waste printing developer using three adsorbents (NZ, $A C$ and their mixture) was most effective within the first 90 minutes of contact. 
The adsorption processes were interpreted in terms of the Freundlich, Langmuir and DKR isotherm models. The experimental data correlated reasonably well by the Freundlich and DKR adsorption isotherms and the isotherm parameters were calculated. It was found that the Freundlich isotherm gave the best agreement over the whole adsorption range; the corresponding correlation coefficients $\left(R^{2}\right)$ being 0.997 . These investigations pointed out that the use of inexpensive adsorbents may be an effective way for remove $\mathrm{Cr}$ (total) ions from waste printing developer. The adsorption capacities of adsorbents show the following decreasing order: $(\mathrm{NZ}+\mathrm{AC})>\mathrm{NZ}>\mathrm{AC}$.

\section{ACKNOWLEDGMENT}

The authors acknowledge the financial support of the Ministry of Science and Technological Development of the Republic of Serbia (Project No. 34014).

\section{REFERENCES}

Arivoli S., Martin P., Deva P. and Thenkuzhali M. (2007) Adsorption of chromium ion by acid activated low cost carbon, Electronic Journal of Environmental, Agricultural and Food Chemistry, 6(9), 2323-2340.

Babel S. and Kurniawan T.A. (2003) Low-cost adsorbents for heavy metals uptake from contaminated water: a review, Journal of Hazardous Materials, 97, 219-243.

Erdem E., Karapinar N. and Donat R. (2004) The removal of heavy metal cations by natural zeolites, Journal of Colloid and Interface Science, 280, 309-314.

Jiuhui Q.U. (2008) Research progress of novel adsorption processes in water purification: a review, Journal of Environmental Sciences, 20, 1-13.

Kiurski J., Vojinovic Miloradov M., Cveticanin L. and Kovacevic S. (2008) The graphic industry and its waste management in Vojvodina, The $15^{\text {th }}$ International Symposium on Analytical and Environmental Problems, Szeged, Hungary, 11-15.

Kiurski J., Vojinovic Miloradov M., Krstic J., Radin Oros I., Adamovic D. and Kovacevic I. (2009) Chemical treatment of wastewater in printing industry, The $16^{\text {th }}$ International Symposium on Analytical and Environmental Problems, Szeged, Hungary, 408-411.

Kiurski J., Adamovic S., Oros I., Krstic J., Grujic S. and Mihailovic A. (2010a) Removal efficiency of Zn(II) ions from waste printing developer, The $7^{\text {th }}$ Aegean Analytical Chemistry Days, Mytilene, Greece, 249-249.

Kiurski J., Prica M., Adamovic S., Oros I. and Krstic J., (2010b) The possibility of metal removal from used printing developer by natural zeolite and activated carbon, SETAC 20; Seville; Spain, 248.

Kocaoba S., Orhan Y. and Akyüz T. (2007) Kinetics and equilibrium studies of heavy metal ions removal by use of natural zeolite, Desalination, 214, 1-10.

Oke I.A., Olarinoye N.O. and Adewusi S.R.A., (2008) Adsorption kinetics for arsenic removal from aqueous solutions by untreated powdered eggshell, Adsorption, 14, 73-83.

Rao G.P.C., Satyaveni S., Ramesh A., Chowdary N.V. and Murthy K.S.N. (2006) Sorption of cadmium and zinc from aqueous solutions by zeolite $4 a$, zeolite $13 x$ and bentonite, Journal of Environmental Management, 81, 265-272.

Rožić M., Bolanča Z. and Cerjan-Stefanović Š. (2004) Natural zeolites and the possibility of their application in the pollutant control in graphic industry, Journal of Chemists and Chemical Engineers, 53 (10), 449-458.

Sprynskyy M., Buszewski B., Terzyk A.P. and Namiesnik J. (2006) Study of the selection mechanism of heavy metal $\left(\mathrm{Pb}^{2+}, \mathrm{Cu}^{2+}, \mathrm{Ni}^{2+}\right.$ and $\left.\mathrm{Cd}^{2+}\right)$ adsorption on clinoptilolite, Journal of Colloid and Interface Science, 304, 21-28.

Vengris T., Binkiene R., Butkiene R., Nivinskiene O., Melvydas V., Manusadzianas L. (2004) Microbiological degradation of a spent offset-printing developer, Journal of Hazardous Materials, B113, 181-187.

Thing-Chu Hsu (2009) Experimental assessment of adsorption of $\mathrm{Cu}^{2+}$ and $\mathrm{Ni}^{2+}$ from aqueous solution by oyster shell powder, Journal of Hazardous Materials, 171, 995-1000.

Thompson G., Swain J., Kay M. and Forster C.F. (2001) The treatment of pulp and paper mill effluent: a review, Bioresource Technology, 77, 275 - 286. 